[Kahu, Ella R. (2008). Feedback: The Heart of Good Pedagogy. New Zealand Annual Review of Education, 17, 187-197]

\section{Feedback: The Heart of Good Pedagogy}

\section{ELLA R. KAHU}

\section{Abstract:}

Researchers agree that while feedback is central to learning it is underresearched and under-theorised. It could also be argued that within the tertiary sector, feedback is also under-utilised. This article reviews the literature on external formal feedback in higher education settings and makes recommendations to help redress this lack. Following a summary of the effects of feedback on achievement and learning, the different levels at which feedback operates, evaluative, motivational, and cognitive, are discussed. Strategies for increasing the efficacy offeedback, in particular timing and focus, are identified. Moves towards more contemporary constructivist understandings of learning have led to a focus on the role of feedback in developing self-regulated learners and how it is mediated by students' beliefs. It is argued that this results in a need for a shift towards a more student-centred view of feedback.

$\mathrm{F}$

eedback can be broadly defined as information provided to learners about their knowledge and/or performance. Ranging from simple praise, to an evaluation in the form of a grade, through to detail about strategies for improvement, the depth and efficacy of feedback vary. While feedback is often provided verbally in the classroom setting, the majority of feedback in tertiary education is delivered as part of formal assessment processes. This type of feedback is often described as formative assessment, defined by Sadler (1998) as assessment that is "intended to provide feedback on performance to improve and accelerate learning" (p. 77).

Most theorists agree feedback is a powerful influence on learning and an essential component of effective teaching. A recent OECD report concluded that formative assessment has resulted in the largest achievement gains ever reported for educational interventions (Centre for Educational Research and Innovation, 2005). Black and Wiliam's review (1998) concluded that feedback increases achievement across all content areas, skill types, and ages. Hattie (1999) has gone a step further by attempting to quantify feedback's power. After synthesising over 300 meta-analyses, he calculated that innovations in education improve achievement on average by 0.4 of a standard deviation. In comparison, 12 meta-analyses covering 196 studies on feedback gave a comparable average effect size of 0.79 (Hattie \& Timperley, 2007). Depending on the nature of the feedback, the effect size varied considerably, highlighting the need to understand different characteristics of feedback such as timing and focus. Before exploring that research, it may be helpful to set the context by giving an overview of the different functions of feedback.

\section{Functions of Feedback}

Arguably the power of feedback is due to its ability to operate at multiple levels with "multifaceted roles in learning" (Butler \& Winne, 1995, p. 246). Feedback can be seen to have three different functions: evaluation, motivation, and learning (Butler \& Winne, 1995; Nicol \& Macfarlane-Dick, 2006; Pithers \& Holland, 2003). Nearly 20 years ago, Sadler (1989) criticised higher education for being excessively concerned with the evaluative function in the form of summative assessment, rather than in the form of the more important formative assessment. A recent Australian survey of university staff also found that summative assessment dominated, suggesting little has changed (Orrell, 2006). This is of concern, as research shows that grades given without accompanying suggestions for improvement and information about existing competencies can undermine intrinsic motivation in a task and therefore can result in reduced interest and performance (Stipek, 1996). Craven, Marsh, and Debus (1991) note too that grades alone have a negative effect on the self esteem of low ability students.

The effect of feedback on motivation is critical, and Berry's (2005) research found that teachers link feedback mostly to the motivational function, that is, encouraging students to continue to behave in ways that get positive feedback and to increase effort and performance in the future. However, she and others comment that researchers have tended to underplay the benefits of motivational feedback (Nicol \& Macfarlane-Dick, 2006). Feedback plays an important role in both social learning theory and attribution theory. Social learning theory sees external feedback as a key source of self-efficacy, an individual's belief 
in their ability to perform a task (Bandura, 1997). To be effective, such feedback needs to highlight both what was done well and what needs improvement (Blanchard \& Thacker, 2003). As Ormrod (1999) points out, constructive criticism tells students that the teacher knows they are capable of improvement, and is thus an important influence on efficacy. Feedback also plays an important role in changing students' attributions, that is, their beliefs about the causes of their performance. Gist and Mitchell (1992) suggest that positive feedback can effectively intervene in the downward spiral in which a student with low self-efficacy attributes failure to lack of ability, and therefore puts less effort into subsequent attempts. Bandura (1997) expresses this well: "the less individuals believe in themselves, the more they need explicit, proximal and frequent feedback of progress that provides repeated affirmations of their growing capabilities" (p. 217). The findings on the effect of feedback on attributions are complex, but Stipek's (1996) synthesis provides some excellent practical guidelines. Feedback increases motivation if it is: clear, frequent, and conveys developing competence; avoids subtly conveying perceptions of low ability such as praising for easy tasks; focuses on mastery rather than norms; emphasises effort and learning rather than being correct; and treats mistakes as normal. While most agree that emphasising effort as the cause of failure is beneficial, there is less agreement as to whether success should be attributed to ability or effort (Stipek, 1996). Hattie and Timperley's (2007) analysis suggests that student responses to feedback vary according to the stage of the task, with effort attributions appearing more credible early in the learning process and ability attributions more credible as skills develop.

The most direct function of feedback is its role in guiding learning. Operant conditioning theory suggests positive feedback acts as a reinforcer and therefore is most beneficial when it is immediate, consistent until learning occurs, and then intermittent to ensure maintenance of the behaviour (Ormrod, 1999). Another important view of how feedback influences learning stems from goal theory. Feedback aims to reduce the discrepancy between current performance and a desired goal. Therefore students must know three things: what good performance is, how current performance compares, and what to do to narrow the gap (Sadler, 1998). While a full explanation of goal theory is beyond the scope of this review, a few findings are worth highlighting. Feedback needs to be directly relevant to goals (Hattie, 1999; Hattie \& Timperley, 2007). It is particularly effective if the goals are specific and challenging (Kluger \& DeNisi, 1996), and if students understand the goals, own them, and are able to assess their own progress (Black \& Wiliam, 1998). Finally, Nicol and Macfarlane-Dick (2006) suggest that students' goals must align with the teacher's goals for feedback to be effective.

\section{Characteristics of Effective Feedback}

Regardless of whether feedback leverages its effect directly or through its impact on motivation, a number of characteristics have been found to be important in increasing achievement. These include timing, quantity, and focus. According to Schroth (1992), the nature of the task and the desired outcome determine whether feedback should be immediate or delayed. For example, Clariana, Wagner, and Roher Murphy (2000) found that delayed feedback was more effective for more difficult tasks, whilst Butler and Winne (1995) have suggested that if transfer of learning strategies is important, then delayed feedback can be more effective, as it gives students time to consider how they learn. The quantity of feedback is also relevant. For example, Nicol and Macfarlane-Dick (2006) suggest limiting the amount, so as to not overwhelm the student, and also prioritising the recommended areas of improvement. As well as timing and quantity, the focus of the feedback influences its effect.

Butler and Winne (1995) distinguish between outcome feedback (correct versus incorrect), and cognitive feedback, which provides information about task cues to help students monitor and improve their performance. Bangert-Drowns, Kulik, Kulik, and Morgan (1991) and Balzer, Doherty, and O'Connor (1989) all found that elaborated cognitive feedback is more effective than mere outcome feedback. Further developing these ideas, Hattie and Timperley (2007) propose four levels of feedback: task, process, self-regulation, and self. Task feedback, such as whether the work is correct, is most common but does not promote the generalisation of skills. Process feedback, which focuses on the learning processes needed for the task, and self-regulation feedback, which addresses students' self-monitoring and selfassessment, both encourage deeper learning and mastery. Self feedback, such as praise, is targeted at the student rather than at performance on the task, and is considered the least effective. However, despite having a low effect size of only 0.09, according to Kluger and DeNisi (1996), praise can increase self-efficacy if it is specific and focuses on effort or engagement (Hattie \& Timperley, 2007). 
Yorke (2003) suggests a similar distinction between convergent feedback, focusing on pre-specified objectives, and divergent feedback, focusing on wider open ended tasks. Pryor and Crossouard (2005) suggest convergent feedback is behaviourist and used to reinforce correct responses, while divergent feedback is "exploratory, provisional or provocative, prompting further engagement rather than correcting mistakes" (p. 2). They argue both types are essential, rather than simply being a good/bad dichotomy.

The contrast between feedback about immediate domain knowledge/task and feedback about learning strategies is part of a trend towards examining the role of feedback in the development of self-regulated learners. Self-regulated learners set goals, select strategies carefully for reaching those goals, and regularly monitor their progress (Butler \& Winne, 1995). According to Nicol and Macfarlane-Dick (2006), self-regulated learners who monitor their own learning processes are more persistent, resourceful, confident, independent, and are likely to be higher achievers. In addition, they generate more self-feedback and interpret and use external feedback more effectively (Butler \& Winne, 1995). Importantly, self-regulation is a learned skill, and feedback can contribute to that process. For example, Carless, Joughin, and Mok (2006) have coined a new term "learning-oriented assessment" to describe feedback which promotes self-assessment and the development of lifelong learning skills. Similarly, Boud (2000) suggests a shift to the term "sustainable assessment" which "meets the needs of the present without compromising the ability of students to meet their own future learning needs" (p. 151). In this context, good feedback is redefined by Nicol and Macfarlane-Dick (2006) as "anything that might strengthen the students' capacity to self regulate their own performance" (p. 205). They suggest seven principles of such feedback. It clarifies good performance, facilitates development of reflection, encourages discussion, encourages positive self esteem, gives opportunities to improve, and gives information that teachers can use to shape their teaching.

\section{Student-Centred Feedback}

This new focus is linked to increasingly constructivist views of learning as a dialogical process. Students do not simply acquire the knowledge - they construct it through the lens of their own experiences and existing knowledge (Nicol \& Macfarlane-Dick, 2006). As Butler and
Winne state, "feedback's influence is conditional on how its information is filtered through a student's existing beliefs" (1995, p. 254). Dweck's (1999) work on self-theories shows that students have different motivational frameworks depending on their beliefs about learning, and this affects their response to feedback. For example, Yorke and Knight (2004) demonstrate that feedback is only effective if the student believes effort and smart thinking can result in improvement. At a different level, Pryor and Crossouard (2005) take a more socio-cultural view and highlight the social nature of formative assessment, noting that it is located both within an immediate classroom context and also a wider social sphere. These views highlight the need for a more student-centred approach to feedback within tertiary education settings.

Yorke (2003) argues that while teaching has become more studentcentred, assessment has not. She makes the critical point that from a student-centred perspective, feedback can only be considered formative if the student actually learns from it. As Hattie and Timperley (2007) remind us, feedback can be ignored, accepted, or modified by the learner. Researchers who have examined feedback from the students' perspective identify four requirements of effective feedback.

First, as Gibbs and Simpson (2004) state, feedback must be attended to. Research on this is inconsistent, with some studies suggesting students ignore feedback and only read the grades (Wojtas, 1998, as cited in Weaver, 2006) while others, such as Higgins, Hartley, and Skelton (2001), found that as many as 97 percent of students read written feedback. Simply reading feedback is not sufficient, however.

Secondly, Sadler (1998) points out that feedback needs to be accessible to the learner. This requirement is highlighted in a survey finding by Gibbs and Simpson (2004) that 30 percent of students reported that feedback did not help them understand. In tertiary education, comments are often framed in an academic discourse which students struggle to understand and translate into effective action (Lea \& Street, 1998; Mutch, 2003). Students may not understand as well as they think they do and comments can be interpreted differently by tutors and students because of "different conceptions of the meaning of terms and phrases" (Read, Francis, \& Robson, 2005, p. 244). For example, Chanock (2000) researched students' understanding of the often used marking comment "too much description, not enough analysis" and found that nearly half the students misinterpreted the comment. Winter, Neal, and Waner (1996) make the important point that students with lower grades may find comments less useful as they are less able 
to understand what is required. A simpler but equally important reason for lack of accessibility of feedback is poor handwriting by markers. For example, in Higgins, Hartley, and Skelton's (2002) research, 40 percent of students found comments hard to read.

A third and related point is that feedback needs to "prompt active information processing on the part of the learners" (Hattie \& Timperley, 2007, p. 104). Understanding of feedback can be greatly enhanced by structured opportunities for reflection and deeper processing. As Higgins et al. (2001) suggest, there needs to be more discussion and collaboration between tutors and students to "reflect on, question, make explicit and share competing understandings" (p. 273).

Finally, Gibbs and Simpson (2004), in outlining the conditions under which assessment supports students' learning, make the obvious but often ignored point that feedback must be acted upon. Orsmond, Merry, and Reiling (2005) argue that most students have "a genuine commitment to applying feedback to improve their mark or learning" (p. 379). Sadler (1998) suggests that for this to happen, feedback needs to be embedded within a second cycle of performance $\rightarrow$ feedback. This is made difficult in the university setting by the fact that most courses do not allow resubmission of assessment tasks and often subsequent assessments are of a different nature. This lack of immediate opportunity to apply feedback can result in students simply reading the comments at the time and then not referring to them again, resulting in no improvement or learning. Tutors therefore need to ensure they provide the broader kind of feedback discussed earlier, which can be transferred across assessment tasks, and which supports self-regulated learning. In addition, students need support to learn to recognise when feedback can be used in this way - both across different courses but also in other spheres of life.

These four requirements indicate the need for a much greater focus on feedback in university courses. As Mutch (2003) argues, lecturers need to modify course design so that it "places reflection on feedback at its heart" (p. 36). Instead of simply returning assessments and expecting students to automatically get the full learning potential from the feedback, lecturers need to schedule what Orsmond et al. (2005) describe as feedforward discussions. After marked assignments are returned to the students, time is allocated for them to read the comments, discuss them in small peer groups, and, most importantly, translate them into actions that they can take to improve in the future. Having the lecturer or tutor available during this time would ensure that any issues with inability either to read or to understand the feedback could be dealt with immediately, and it would enable the kind of active discussion that research suggests is needed for students to truly understand and act on feedback (Higgins et al., 2001). This strategy would also centralise the important role that feedback has in producing self-regulating learners (Butler \& Winne, 1995).

\section{Conclusion}

Feedback is clearly a critical influence on student achievement and is therefore deserving of a much greater focus in both research and practice. The research summarised here results in clear recommendations for the provision of effective feedback in tertiary settings. It must be:

- timely,

- not overwhelming,

- positive and constructive,

- linked to goals, and

- focused on both the immediate task and domain as well as the deeper learning processes.

In addition, the growing awareness that feedback should be a two-way dialogue and not a one-way transmission suggests a need for a greater focus on the learners' role in the feedback process. Practitioners need to provide structured sessions for students to read and process the feedback they receive. Further research is also needed to explore how the efficacy of such sessions can be maximised.

\section{References}

Balzer, W. K., Doherty, M. E., \& O'Connor, R. (1989). Effects of cognitive feedback on performance. Psychological Bulletin, 106(3), 410-433.

Bandura, A. (1997). Self efficacy: The exercise of control. New York: W. H. Freeman.

Bangert-Drowns, R. L., Kulik, C. C., Kulik, J. A., \& Morgan, M. (1991). The instructional effect of feedback in test-like events. Review of Educational Research, 61(2), 213-238.

Berry, R. (2005). Functional significance of feedback in learning. Paper presented at the conference of the Australian Association for Research in Education (AARE), Parramatta, Australia. 
Black, P., \& Wiliam, D. (1998). Assessment and classroom learning. Assessment in Education, 5(1), 7-74.

Blanchard, P. N., \& Thacker, J. W. (2003). Effective training: Systems, strategies, and practices (2nd ed.). New Jersey: Pearson/Prentice-Hall.

Boud, D. (2000). Sustainable assessment: Rethinking assessment for the learning society. Studies in Continuing Education, 22(2), 151-167.

Butler, D. L., \& Winne, P. H. (1995). Feedback and self-regulated learning: A theoretical synthesis. Review of Educational Research, 65(3), 245-281.

Carless, D., Joughin, G., \& Mok, M. M. C. (2006). Learning-oriented assessment: Principles and practice. Assessment and Evaluation in Higher Education, 31(4), 395-398.

Centre for Educational Research and Innovation. (2005). Formative assessment: Improving learning in secondary classrooms. Paris: OECD.

Chanock, K. (2000). Comments on essays: Do students understand what tutors write? Teaching in Higher Education, 5(1), 95-105.

Clariana, R. B., Wagner, D., \& Roher Murphy, L. C. (2000). Applying a connectionist description of feedback timing. Educational Technology Research and Development, 48(3), 5-21.

Craven, R. G., Marsh, H. W., \& Debus, R. L. (1991). Effects of internally focused feedback and attributional feedback on enhancement of academic self-concept. Journal of Educational Psychology, 83(1), 17-27.

Dweck, C. S. (1999). Self-theories: Their role in motivation, personality and development. Philadelphia, PA: Psychology Press.

Gibbs, G., \& Simpson, C. (2004). Conditions under which assessment supports students' learning. Learning and Teaching in Higher Education, 1, 3-31.

Gist, M. E., \& Mitchell, T. R. (1992). Self-efficacy: A theoretical analysis of its determinants and malleability. Academy of Management Review, 17(2), 183-207.

Hattie, J. (1999). Influences on student learning. Retrieved September 4, 2007, from <www.arts.auckland.ac.nz/staff/index.cfm? $\mathrm{P}=8650>$.

Hattie, J., \& Timperley, H. (2007). The power of feedback. Review of Educational Research, 77(1), 81-112.

Higgins, R., Hartley, P., \& Skelton, A. (2001). Getting the message across: The problem of communicating assessment feedback. Teaching in Higher Education, 6(2), 269-274.
Higgins, R., Hartley, P., \& Skelton, A. (2002). The conscientious consumer: Reconsidering the role of assessment feedbackin student learning. Studies in Higher Education, 27(1), 53-64.

Kluger, A. N., \& DeNisi, A. (1996). The effects of feedback interventions on performance: A historical review, a meta-analysis, and a preliminary feedback intervention theory. Psychological Bulletin, $119(2), 254-284$

Lea, M., \& Street, B. (1998). Student writing in higher education: An academic literacies approach. Studies in Higher Education, 23(2), $157-172$.

Mutch, A. (2003). Exploring the practice of feedback to students. Active Learning in Higher Education, 4(1), 24-38.

Nicol, D. J., \& Macfarlane-Dick, D. (2006). Formative assessment and self-regulated learning: A model and seven principles of good feedback practice. Studies in Higher Education, 31(2), 199-218.

Ormrod, J. E. (1999). Human learning. Upper Saddle River, NJ: Prentice-Hall.

Orrell, J. (2006). Feedback on learning achievement: Rhetoric and reality. Teaching in Higher Education, 11(4), 441-456.

Orsmond, P., Merry, S., \& Reiling, K. (2005). Biology students' utilization of tutors' formative feedback: A qualitative interview study. Assessment and Evaluation in Higher Education, 30(4), 369-386.

Pithers, B., \& Holland, T. (2003). A study of the purposes and importance of assessment feedback. Australian Vocational Educational Review, 10(1), 15-20.

Pryor, J., \& Crossouard, B. (2005). A sociocultural theorization of formative assessment. Paper presented at the Sociocultural Theory in Educational Research and Practice Conference, University of Manchester.

Read, B., Francis, B., \& Robson, J. (2005). Gender, "bias", assessment and feedback: Analyzing the written assessment of undergraduate history essays. Assessment and Evaluation in Higher Education, 30(3), 241-260.

Sadler, D. R. (1989). Formative assessment and the design of instructional systems. Instructional Science, 18, 119-144.

Sadler, D. R. (1998). Formative assessment: Revisiting the territory. Assessment in Education, 5(1), 77-84. 
Schroth, M. L. (1992). The effects of delay of feedback on a delayed concept formation transfer task. Contemporary Educational Psychology, $17,78-82$.

Stipek, D. J. (1996). Motivation and instruction. In D. C. Berliner \& R. C. Calfee (Eds.), Handbook of educational psychology (pp. 85-113). New York: Macmillan.

Weaver, M. R. (2006). Do students value feedback? Student perceptions of tutors' written responses. Assessment and Evaluation in Higher Education, 31(3), 379-394.

Winter, J. K., Neal, J. C., \& Waner, K. K. (1996). Student and instructor use of comments on business communication papers. Business Communication Quarterly, 59(4), 56-68.

Yorke, M. (2003). Formative assessment in higher education: Moves towards theory and the enhancement of pedagogic practice. Higher Education, 45, 477-501.

Yorke, M., \& Knight, P. (2004). Self-theories: Some implications for teaching and learning in higher education. Studies in Higher Education, 29(1), 26-37.

\section{The author}

Ella Kahu completed her Master of Arts in Psychology in 2006 with a thesis which critically examined the discursive impact of government policy on women's life/work choices. In a separate life arena, her success in national speaking competitions resulted in the development of a small business, teaching presentation skills for both corporate and academic audiences. The desire to understand and improve the process of educating adults, in both training and tertiary settings, has led to her recently completing a Postgraduate Diploma in Education and Professional Development at Victoria University of Wellington. As well as continuing to teach presentation skills, Ella is currently teaching undergraduate psychology at Massey University in Wellington. 